\title{
A DISCRIMINAÇÃO POSITIVA COMO GARANTIA DE IGUALDADE AOS HOMOSSEXUAIS
}

\author{
POSITIVE DISCRIMINATION AS A GUARANTEE OF EQUALITY FOR \\ HOMOSEXUALS
}

\author{
${ }^{1}$ Letícia Vasconselos Barcellos \\ ${ }^{2}$ Phillip Gil França
}

\section{RESUMO}

O artigo analisa as discriminações lícitas criadas para alcançar a igualdade entre os indivíduos, como as decisões judicias favoráveis aos homossexuais e os projetos de lei que visam atribuir-lhes garantia efetiva de seus direitos. Para tanto, foram estudados a origem da homoafetividade, a importância dos princípios constitucionais para edificação dos direitos, o direito à liberdade de sexo e os avanços jurisprudenciais no sentido de reconhecimento de direitos dos homossexuais. O trabalho foi estruturado com base na metodologia hipotéticodedutiva, e o estudo se desenvolveu por meio de pesquisas bibliográficas doutrinárias, bases legislativas e jurisprudenciais.

Palavras-chave: Discriminações lícitas. Homoafetividade. Igualdade. Liberdade de sexo. Princípios constitucionais.

\begin{abstract}
The article analyzes the legal discrimination designed to achieve equality between individuals, as decisions judicial favorable to homosexuals and the law projects that aim to give them effective guarantee of their rights. To this end, we studied the origin of homoafetividade, the importance of the constitutional principles for the edification of the rights, the right to freedom of sex and the advances in the jurisprudential sense of recognition of rights of homosexuals. The work was structured on the basis of the methodology hypothetical-deductive, and the study was developed through research, doctrinal foundations laws and jurisprudence.
\end{abstract}

Keywords: Licit discrimination. Homoaffective. Equality. Freedom of sex. Constitutional principles.

\footnotetext{
${ }^{1}$ Mestranda pelo Programa de Pós Graduação stricto sensu - Mestrado em Direito pela Universidade de Passo Fundo (UPF) Passo Fundo, Rio Grande do Sul, Brasil. Email: le_barcellos@ hotmail.com

${ }^{2}$ Pós-doutor (CAPES_PNPD), Doutor e Mestre em Direito do Estado pela (PUC/RS), Rio Grande do Sul, Brasil. Professor de Direito Administrativo e Hermenêutica Jurídica pela Universidade de Passo Fundo (UPF) Passo Fundo, Rio Grande do Sul, Brasil. Email: tutortreinamneto@gmail.com
} 


\section{INTRODUÇÃO}

O contexto histórico atual retrata inúmeras mudanças no sentido de se derrubar determinados preconceitos, principalmente com relação aos homossexuais, que, por meio de decisões judiciais e políticas de afirmação de seus direitos, têm assegurados suas garantias constitucionais de dignidade da pessoa humana.

Os homossexuais ainda são alvos de atitudes discriminatórias em razão de uma cultura preconceituosa enraizada na atual sociedade brasileira, motivo pelo qual se faz necessário instituir movimentos de afirmação de direitos humanos e de igualdade entre os indivíduos, além de ser importantíssimo o reconhecimento da equivalência de direitos dos casais heterossexuais com os casais homoafetivos, pelo Judiciário.

Desta maneira, tendo ampliado o rol de garantias concernentes a estas uniões, cada vez mais os Tribunais vem concedendo direitos de toda ordem às famílias formadas por casais do mesmo sexo, ao que se infere da densa jurisprudência atual definindo, por exemplo, direitos à benefícios previdenciários, sucessão e direito a adotar.

Ao passo em que os julgadores tomam consciência da realidade social, buscando sua adequação à evolução compassada do direito, aparentemente, o legislador permanece escondido sob o véu de uma possível omissão discriminatória. Porém, mostra-se necessário aplicar a letra da Constituição Federal de forma efetiva, garantindo a igualdade real dos indivíduos, mesmo que somente as próximas gerações desfrutem de tal liberdade.

\section{HOMOSSEXUALIDADE E PRECONCEITO}

Relatos comprovam experiências homoafetivas tratadas com naturalidade na Grécia Antiga, onde se exaltava o corpo masculino e a figura do homem como ser superior à mulher. Eram enaltecidas as relações de afeto entre homens, e à mulher era atribuída a mera função de procriação.

A homoafetividade passou a ser tratada como tabu (também) a partir do ideal de família imposto pela Igreja Católica, que primava pela relação heterossexual, pautada exclusivamente no matrimônio e com o objetivo de constituir a prole. Assim, uniões formadas de modo diferente passaram a ser discriminadas pela Igreja e por quem se considerava dentro do padrão estabelecido, ou seja, as relações homoafetivas foram estigmatizadas, vistas como desvirtuadas e relegadas à margem da sociedade. 
O estereótipo criado pela moralidade judaico-cristã afastou os homossexuais do padrão convencionado e ainda trouxe discussões intermináveis sobre a origem desse comportamento considerado por muitos como anormal. Não resta esclarecido se provém de questões genéticas, médicas, psiquiátricas ou de experiências de infância, mas é certo que se trata de uma característica inerente ao indivíduo, um comportamento resultante de sua personalidade, um direito fundamental à liberdade sexual do qual não se pode abdicar.

Por este motivo, as uniões homoafetivas estão a receber o respaldo que se tem buscado. Ainda que haja uma propensa omissão legislativa no sentido de reconhecer a legitimidade dessas uniões, os Tribunais de Justiça de alguns estados apresentam decisões voltadas a tutelar os direitos das uniões homoafetivas, tendo por base princípios fundamentais como da igualdade e da dignidade da pessoa humana.

Apesar desse novo cenário, sabe-se que ainda persistem barreiras difíceis de ultrapassar, o que talvez seja o combustível para que aqueles discriminados por suas diferenças se mantenham na luta por igualdade de direitos e oportuidades.

Para Michel Foucault, quanto maior a repressão ao sexo, pela Igreja ou mesmo pelos padrões sociais de moralidade, maior é a ânsia para que seja manifestado em suas várias formas.

\footnotetext{
O homossexual do século XIX torna-se uma personagem: um passado, uma história, uma infância, um caráter, uma forma de vida; também é morfologia, com uma anatomia indiscreta e, talvez, uma fisiologia misteriosa. Nada daquilo que ele é, no fim das contas, escapa à sua sexualidade. Ela está presente nele todo: subjacente a todas as suas condutas, já que ela é o princípio insidioso e infinitamente ativo das mesmas; inscrita sem pudor na sua face e no seu corpo já que é um segredo que se trai sempre. (1997, p. 43)
}

O exame médico, a investigação psiquiátrica, o relatório pedagógico e os controles familiares podem, muito bem, ter como objetivo global e aparente dizer não a todas as sexualidades errantes ou improdutivas, mas na realidade, funcionam como mecanismo de dupla incitação: prazer e poder (FOUCAULT, 1997, p. 45).

Nossa sociedade é terminantemente excludente em todos os sentidos, seja por questões de etnia, classe social gênero ou sexualidade. São acaloradas as discussões sobre orientação sexual, relações homoafetivas e novos núcleos familiares formados pelas relações de afeto e não somente pelo casamento.

Sobre a questão da liberdade concedida a cada um, Foucault discorre que mesmo os gregos, que praticavam a homossexualidade de forma natural, seguiam uma norma de conduta 
de abstenção. Os gregos praticaram, aceitaram e valorizaram as relações entre homens e rapazes, e, contudo, seus filósofos conceberam e edificaram, a esse respeito, uma moral da abstenção. Eles admitiram perfeitamente que um homem casado pudesse procurar seus prazeres sexuais fora do casamento, e, no entanto, seus moralistas conceberam o princípio de uma vida matrimonial em que o marido só teria relação com a própria esposa. (FOUCAULT, 1994, p.89)

A discriminação pode ser compreendida como toda forma de exclusão, seja por questões de crença, gênero, deficiência, opção sexual, nacionalidade, com o intuito de privar da igualdade e do reconhecimento de direitos.

Porém, de acordo com o que se extrai do texto de Álvaro Ricardo de Souza Cruz (2003, p. 21-22), é absurdo afirmar que toda discriminação é odiosa ou incompatível com os preceitos do constitucionalismo contemporâneo. Muitas vezes, estabelecer uma diferença, distinguir ou separar é necessário e indispensável para a garantia do próprio princípio da isonomia, ou seja, para que a noção de igualdade atenda às exigências do princípio da dignidade humana e da produção discursiva.

Para tanto, se traz a ideia de desigualdades permitidas para que os desiguais atinjam a igualdade, desde que realmente seja aplicado às minorias que necessitem desta distinção e que esteja de acordo com o que consta estabelecido na Constituição.

Refere Souza Cruz (2003, p. 30), são legítimas as normas constitucionais que determinem distinções de gênero, impondo benefício/preferência que se estabelece em prol da mulher no tocante à licença-maternidade e tempo de contribuição para aposentadoria, implicando em sentido reverso, uma restrição para o homem.

As discriminações surgem de diferentes contextos e geram uma ideia preconcebida que se torna conhecimento popular através dos costumes e da cultura, criando um estigma sobre determinado grupo que se torna alvo de julgamento.

Conforme pontua Souza Cruz,

\begin{abstract}
A violação dos direitos fundamentais através da discriminação pode se manifestar de diferentes maneiras. A primeira delas, mas não a mais comum no Brasil, é a discriminação direta ou intencional, ou seja, uma conduta da qual se depreende facilmente o animus discriminatório, ou seja, o dolo, a vontade de violar o direito de outrem. Nela está presente a premeditação, a vontade de violar a integridade física e moral do outro. (2003, p. 42).
\end{abstract}

Além disso, existe a discriminação de fato, entendida como as frequentes graças e ironias, uma forma descontraída que não retira o caráter ofensivo. Outra forma de 
discriminação de fato resulta de uma política de neutralidade e de indiferença do aparato estatal para com as vítimas da discriminação. Nesse sentido, as minorias não conseguem fazer com que recebam um tratamento diferenciado em razão de suas peculiaridades étnicas, culturais e sociais. (SOUZA CRUZ, 2003, p. 44)

O desrespeito aos princípios constitucionais fere o âmago do significado de igualdade, e todas as lutas sociais ocorridas para se chegar ao mínimo de respeito que se tem hoje por determinados grupos marginalizados, são completamente desprezadas.

O que se busca com uma Constituição em um país é utilizar dos princípios para alcançar o máximo de inclusão social, valorizando seu povo em todas as suas diferenças, não apenas fundamentar belos discursos sem intenção de agir.

Para demonstrar o quanto se precisa evoluir no sentido de igualar e respeitar as diversidades, importante destacar o exposto por Roger Raupp Rios (s.d. p. 2), o Brasil é conhecido como um dos países em que há o maior número de assassinatos por orientação sexual. Há dados estatísticos - não tão precisos, porque há dificuldade em sua realização - de que a cada dois dias uma pessoa é assassinada no Brasil em função de sua orientação sexual, informação absolutamente avassaladora.

Raupp Rios, sobre a ideia de tolerância e o quanto o tema da homossexualidade é debatido ou mascarado em alguns ordenamentos, sustenta o seguinte:

\begin{abstract}
Caracterizo três grandes maneiras com que os ordenamentos jurídicos encaram a homossexualidade. Em primeiro lugar, há o modelo de reconhecimento - mínimo da orientação homossexual dentro dos ordenamentos jurídicos, que, efetivamente e simplesmente, não criminaliza a conduta ou a atração homossexual; em segundo lugar, existem ordenamentos jurídicos ao redor do mundo que, além de não a criminalizarem, proíbem sua discriminação - modelo denominado de reconhecimento intermediário - e há os que, além disso, incluem medidas de promoção da igualdade e da diversidade, debatendo os fundamentos filosóficos de tais medidas. Entretanto, há ordenamentos jurídicos vigentes atualmente que criminalizam o homossexualismo. [...] No Brasil, desde nosso descobrimento até 1830, tivemos o modelo proibitivo. As Ordenações Filipinas simplesmente criminalizavam a prática da sodomia e de outras animalias como um crime contra Deus e contra os homens, que era punido com a morte, a qual era seguida com a queima do corpo do criminoso na fogueira. (s.d. p. 5).
\end{abstract}

Desde estas barbáries até os dias de hoje, em que pese haja discussões acerca do assunto, reconhecimento pelos julgadores e força dos movimentos sociais pelos direitos $\mathrm{LGBT}^{3}$, o preconceito da época permanece enraizado na cultura e na educação das pessoas, sendo necessária uma mudança de mentalidade.

\footnotetext{
${ }^{3}$ Antigamente como GLS (Gays, Lésbicas e simpatizantes) e atualmente como LGBT, a sigla indicada refere-se a: Lésbicas, Gays, Bissexuais, Transgéneros, Transexuais e Simpatizantes. Como a própria sigla e o seu conceito
} 
No que se refere à proteção das garantias dos homossexuais e à possibilidade de que constitua família, inúmeros paradigmas foram quebrados para se chegar ao reconhecimento que hoje existe por parte dos Tribunais de Justiça dos estados. Essas mudanças se deram pela ampliação do conceito de família disposto na Constituição Federal, que passou a considerar o instituto da união estável como forma de constituir família além do casamento.

Assim, segundo Maria Berenice Dias (2010, p. 2) foi derrogada toda a legislação que hierarquizava homens e mulheres, bem como a que estabelecia diferenciações entre os filhos pelo vínculo existente entre os pais. Ao outorgar proteção à família, independentemente da celebração do casamento, vincou a Carta Magna um novo conceito de entidade familiar, albergando vínculos afetivos outros.

O direito a tratamento igualitário independe da tendência sexual. Inexistindo o pressuposto da igualdade, haverá dominação e sujeição, não liberdade. A sexualidade é um elemento integrante da própria natureza humana e abrange a dignidade humana. Todo ser humano tem o direito de exigir respeito ao livre exercício da sexualidade. (DIAS, 2010, p. 4)

Em razão da omissão legislativa e das inúmeras formas de preconceito contra os homossexuais, a partir dos princípios da igualdade e dignidade teve início a evolução jurisprudencial no sentido de garantir direitos aos casais homoafetivos, primeiramente, com a decisão do Tribunal de Justiça do Rio Grande do Sul em dispor no âmbito do Direito de Família todas as questões concernentes às uniões homoafetivas.

Nesse sentido, importante destacar o estabelecido pelo Conselho Nacional de Justiça no ano de 2013, ao definir como obrigatório aos Cartórios de todo o país celebrar casamento entre casais do mesmo sexo e também converter união estável em casamento ${ }^{4}$, uma vez que ainda em 2011 o Supremo Tribunal Federal reconheceu a união estável entre casais homoafetivos, não deixando dúvidas sobre a legitimidade destas uniões. Na época, o ministro Ayres Britto destacou o art. $3^{\circ}$, inciso IV da Constituição Federal que proíbe discriminações em razão de sexo, cor, raça, sendo descabido o fato de uma pessoa ser discriminada por sexo ou opção sexual. Deixou certo que a orientação sexual de cada um não pode servir de pretexto

indicam não é necessário ter traços ou características homossexuais para se identificar dentro do conceito LGBT, os simpatizantes também são englobados, visto que prestam o seu apoio a toda esta comunidade.

${ }^{4}$ RESOLUÇÃO N ${ }^{\circ}$ 175, DE 14 DE MAIO DE 2013: Art. $1^{\circ}$ É vedada às autoridades competentes a recusa de habilitação, celebração de casamento civil ou conversão de união estável em casamento entre pessoas do mesmo sexo. 
para desigualdades, e, concluiu que a não observação do disposto no artigo $3^{\circ}$ inciso IV fere princípio constitucional ${ }^{5}$.

No ano de 2015, o STF reconheceu em definitivo o direito de um casal homossexual em adotar uma criança ao negar recurso do Ministério Público do Paraná e manter a decisão que autorizava a adoção de criança pelo casal. Na decisão, a ministra Carmen Lúcia fundamentou que a entidade familiar não pode ser restrita por se tratar de casais homoafetivos ${ }^{6}$.

Ademais, para Berenice Dias, o núcleo do atual sistema jurídico é o respeito à dignidade humana, atentando nos princípios da liberdade e da igualdade. A identificação da orientação sexual está condicionada à identificação do sexo da pessoa escolhida em relação a quem escolhe, e tal escolha não pode ser alvo de tratamento diferenciado. Se todos são iguais perante a lei, sem distinção de qualquer natureza, aí está incluída, por óbvio, a orientação sexual que se tenha. (2010, p. 6)

Não há fundamento para proibir uma conduta afetiva, tampouco privar que seja constituída família com base no afeto. O preconceito não deve servir de argumento para opiniões contrárias e para coibir a homoafetividade, um debate justo e o efetivo reconhecimento do direito ao livre exercício da sexualidade é uma necessidade premente.

\section{DIREITOS FUNDAMENTAIS E O DIREITO À LIBERDADE SEXUAL COMO FUNDAMENTAL}

A sexualidade, para Berenice Dias (2010, p. 4), é um direito fundamental que acompanha o ser humano desde o seu nascimento, pois decorre de sua própria natureza. Como

\footnotetext{
${ }^{5}$ Ementa: 1. ARGUIÇÃO DE DESCUMPRIMENTO DE PRECEITO FUNDAMENTAL (ADPF). PERDA PARCIAL DE OBJETO. RECEBIMENTO, NA PARTE REMANESCENTE, COMO AÇÃO DIRETA DE INCONSTITUCIONALIDADE. UNIÃO HOMOAFETIVA E SEU RECONHECIMENTO COMO INSTITUTO JURÍDICO. CONVERGÊNCIA DE OBJETOS ENTRE AÇÕES DE NATUREZA ABSTRATA. JULGAMENTO CONJUNTO. Encampação dos fundamentos da ADPF n ${ }^{\circ} 132-R J$ pela ADI $n^{\circ} 4.277-D F$, com a finalidade de conferir "interpretação conforme à Constituição" ao art. 1.723 do Código Civil. 2. PROIBIÇÃO DE DISCRIMINAÇÃO DAS PESSOAS EM RAZÃO DO SEXO, SEJA NO PLANO DA DICOTOMIA HOMEM/MULHER (GÊNERO), SEJA NO PLANO DA ORIENTAÇÃO SEXUAL DE CADA QUAL DELES. A PROIBIÇÃO DO PRECONCEITO COMO CAPÍTULO DO CONSTITUCIONALISMO FRATERNAL. HOMENAGEM AO PLURALISMO COMO VALOR SÓCIO-POLÍTICO-CULTURAL. LIBERDADE PARA DISPOR DA PRÓPRIA SEXUALIDADE, INSERIDA NA CATEGORIA DOS DIREITOS FUNDAMENTAIS DO INDIVÍDUO, EXPRESSÃO QUE É DA AUTONOMIA DE VONTADE. DIREITO À INTIMIDADE E À VIDA PRIVADA. CLÁUSULA PÉTREA.

6 Decisão. RECURSO EXTRAORDINÁRIO. CONSTITUCIONAL. RECONHECIMENTO DE UNIÃO ESTÁVEL HOMOAFETIVA E RESPECTIVAS CONSEQUÊNCIAS JURÍDICAS. ADOÇÃO. AÇÃO DIRETA DE INCONSTITUCIONALIDADE N ${ }^{\circ}$ 4.277. ACÓRDÃO RECORRIDO HARMÔNICO COM A JURISPRUDÊNCIA DO SUPREMO TRIBUNAL FEDERAL. RECUSRO EXTRAORDINÁRIO AO QUAL SE NEGA SEGUIMENTO.
} 
direito do indivíduo, é um direito natural, inalienável e imprescritível. Ninguém pode realizarse como ser humano se não tiver assegurado o respeito ao exercício da sexualidade, conceito que compreende a liberdade sexual e a liberdade da livre orientação sexual.

Quanto ao fato de a sexualidade estar atrelada ao ser, e por este motivo a opção sexual não se tratar de escolha, mas de característica, Jean-Claude Bernardet leciona:

\begin{abstract}
O adolescente, cujos desejos se encaminham para pessoas do outro sexo, não conhece essa situação. Não só porque ele não é objeto dessa campanha, como porque a sociedade lhe oferece modelos de comportamento. Os meninos namoram com as meninas, e as meninas com os meninos, os pais fizeram assim, os avôs fizeram assim. O casamento, passando ou não pelas leis e pela igreja, está aí: é só fazer como os outros. O casamento monogâmico e o adultério, os bordéis e as prostitutas: o caminho já está traçado. Os romances, os filmes, a publicidade nos muros da cidade ou na televisão, as telenovelas, tudo nos diz como devemos proceder. É o reino da heterossexualidade. Ao adolescente com tendências homossexuais não se oferecem trilhas prontas, ele tem que encontrar as suas, adivinhar, procurar, inventar. É a luta. (1999, pp. 30-31)
\end{abstract}

Assim, como observa Souza Cruz (2003, p. 36), o respeito à diferença só pode ser fruto de um esforço contínuo, uma vez que a maioria, não reconhecendo como cidadão integrante de outro grupo, geralmente rejeita-o. É uma tendência etnocêntrica, que se registra pelos antropólogos em todos os grupamentos humanos.

Para que a diversidade seja tratada com maior espontaneidade futuramente, cabe alterar alguns padrões que ainda sobrevivem, e, neste sentido, começar debatendo o tema da homossexualidade com uma intensidade maior, intuindo extinguir os estereótipos e elevar o tema ao patamar de direito fundamental que nasce com o indivíduo.

Assim, ao demonstrar a mutabilidade do indivíduo conforme os padrões que lhe são ensinados, importante referir o explicitado por Clifford Geertz.

\begin{abstract}
A imagem de uma natureza humana constante, independente de tempo, lugar e circunstância, de estudos e profissões, modas passageiras e opiniões temporárias, pode ser uma ilusão, que o que o homem é pode estar tão envolvido com onde ele está, quem ele é e no que ele acredita, que é inseparável deles. É precisamente o levar em conta tal possibilidade que deu margem ao surgimento do conceito de cultura e ao declínio da perspectiva uniforme do homem. O que quer que seja que a antropologia moderna afirme - e ela parece ter afirmado praticamente tudo em uma ou outra ocasião - , ela tem a firme convicção de que não existem de fato homens não modificados pelos costumes de lugares particulares, nunca existiram e, o que é mais importante, não o poderiam pela própria natureza do caso. $(1989$, p. 26)
\end{abstract}

Ainda, o autor complementa, afirmando que nossas ideias, nossos valores, nossos atos, até mesmo nossas emoções são, como nosso próprio sistema nervoso, produtos culturais — na verdade, produtos manufaturados a partir de tendências, capacidades e disposições com as quais nascemos, e, não obstante, manufaturados. (GEERTZ, 1989, p.62) 
Se ainda hoje resistem os costumes de um hábito antecedente de discriminar e ridicularizar, pode-se converter esta cultura em um princípio de respeito e acatamento das diferenças. O direito à livre escolha sexual como fundamental ao indivíduo deve estar atrelado na sociedade assim como os direitos à livre manifestação do pensamento e à liberdade de consciência.

Em se tratando de direitos fundamentais, importante referir as considerações de Ingo Wolfgang Sarlet acerca do tema, esclarecendo que os direitos fundamentais sofreram inúmeras mudanças quanto ao seu conteúdo e eficácia em razão dos diferentes contextos históricos e sociais em que surgiram, desde as primeiras Constituições. Neste sentido, explica a existência de três gerações de direitos.

Os direitos fundamentais da primeira dimensão são apresentados como direitos de cunho "negativo", uma vez que dirigidos a uma abstenção, e não a uma conduta positiva por parte dos poderes públicos, sendo, neste sentido, "direitos de resistência" ou de oposição perante o Estado (SARLET, 2004, p. 54).

Ainda, o autor explica as categorias destes direitos,

\begin{abstract}
Assumem particular relevo no rol desses direitos, especialmente pela sua notória inspiração jusnaturalista, os direitos à vida, à liberdade, à propriedade e à igualdade perante a lei. São posteriormente, complementados por um leque de liberdades, incluindo as assim denominadas liberdades de expressão coletiva (liberdades de expressão, imprensa, manifestação, reunião, associação, etc) e pelos direitos de participação política, tais como o direito de voto e a capacidade eleitoral passiva, revelando de tal sorte, a íntima correlação entre os direitos fundamentais e a democracia. (2004, p. 55).
\end{abstract}

Quanto aos direitos de segunda dimensão, compreendem os direitos sociais concernentes ao indivíduo concedidos pelo Estado, como o acesso à saúde, educação, assistência social, trabalho, moradia, além dos direitos básicos aos trabalhadores, como garantia de salário mínimo, férias, limitação da jornada de trabalho dentre outros nesse âmbito.

Importante ressaltar que a expressão utilizada "social" denota que, os direitos da segunda dimensão podem ser considerados uma densificação do princípio da justiça social, além de corresponderem às reivindicações das classes menos favorecidas, de modo especial da classe operária, a título de compensação, em virtude da extrema desigualdade que caracterizava (e, de certa forma, ainda caracteriza) as relações com a classe empregadora, notadamente detentora de um maior ou menor grau de poder econômico. (SARLET, 2004, p. $56)$. 
Ao abordar os direitos da terceira dimensão, pode se inferir que trata dos direitos protetivos dos grupos humanos, da família, da nação, sempre abrangendo a coletividade, o ser humano como detentor primeiro de garantias.

Assim, para exemplificar, Sarlet (2004, p. 58) constata que, neste contexto, costumam ser feitas referências às garantias contra manipulações genéticas, ao direito de morrer com dignidade, ao direito à mudança de sexo, igualmente considerados, por parte da doutrina, de direitos da terceira dimensão, ressaltando-se que, para alguns, já se cuida de direitos de uma quarta dimensão.

O autor faz referência a uma quarta dimensão de direitos fundamentais e da possibilidade de admitir uma dimensão que albergue os direitos à democracia e à informação como um novo retrato dos direitos fundamentais, em razão das novas situações que se vive hoje, dos novos casos de reivindicação de direitos. Inclui as garantias de exigir ética nas manipulações genéticas, de ter a possibilidade de mudança de sexo e outras questões norteadas pelo conceito de bioética ${ }^{7}$.

Sendo a homoafetividade um direito à livre escolha da opção sexual, garantia de liberdade de pensamento e manifestação prevista nos direitos de primeira dimensão, deveria esta ser reconhecida sem divergências e de maneira contundente.

De acordo com o exposto por Sarlet,

\begin{abstract}
Com efeito, sendo correta a premissa de que os direitos fundamentais constituem ainda que com intensidade variável - explicitações da dignidade da pessoa, por via de consequência e, ao menos em princípio, em cada direito fundamental se faz presente um conteúdo ou, pelo menos, alguma projeção da dignidade da pessoa. Em suma, o que se pretende sustentar de modo mais enfático é que a dignidade da pessoa humana, na condição de valor (e princípio normativo) fundamental que "atrai o conteúdo de todos os direitos fundamentais", exige e pressupõe o reconhecimento e proteção dos direitos fundamentais de todas as dimensões (ou gerações, se assim preferirmos). Assim, sem que se reconheçam à pessoa humana os direitos fundamentais que lhe são inerentes, em verdade estar-se-á lhe negando a própria dignidade. (2001, p. 87).
\end{abstract}

Assevera Berenice Dias (2010, p. 1), a regra maior da Constituição brasileira é a que consagra o respeito à dignidade humana, servindo de norte ao sistema jurídico nacional. Este é o pressuposto do Estado Democrático de Direito, conforme expressamente proclama o art. $1^{\circ}$, inciso III, da Constituição Federal. Esse compromisso assenta-se nos princípios da

\footnotetext{
${ }^{7}$ A Bioética é uma ética aplicada, chamada também de "ética prática”[1], que visa "dar conta" dos conflitos e controvérsias morais implicados pelas práticas no âmbito das Ciências da Vida e da Saúde do ponto de vista de algum sistema de valores (chamado também de "ética").
} 
igualdade e da liberdade, sendo consagrados já no preâmbulo da norma maior do ordenamento jurídico.

$\mathrm{O}$ art. $5^{\circ}$ da Carta Constitucional, ao elencar os direitos e garantias fundamentais, consagra: todos são iguais perante a lei, sem distinção de qualquer natureza. Garante o mesmo dispositivo, modo expresso, o direito à liberdade e à igualdade. (DIAS, 2010, p. 1).

A grande questão está em efetivar o reconhecimento desta igualdade com relação aos homossexuais, e, é neste sentido que toda ação afirmativa que corrija as desigualdades presentes na sociedade garantindo a liberdade de expressão desse grupo, é válida para futuramente moldar uma legislação protetiva da homoafetividade.

Desimporta a identificação do sexo do par, se igual ou diferente, para se emprestarem efeitos jurídicos aos vínculos afetivos, no âmbito do Direito de Família. Atendidos os requisitos legais para a configuração da união estável, necessário que sejam conferidos direitos e impostas obrigações independentemente da identidade ou diversidade de sexo dos conviventes. (DIAS, 2010, p. 2-3).

A autora afirma ainda que, o direito à homoafetividade, além de estar amparado pelo princípio fundamental da isonomia, cujo corolário é a proibição de discriminações injustas, também se alberga sob o teto da liberdade de expressão. Como garantia do exercício da liberdade individual, igualmente cabe ser incluído entre os direitos de personalidade, precipuamente no que diz com a identidade pessoal e a integridade física e psíquica. (DIAS, 2010, p. 3).

Dessa maneira, pode se ressaltar que o tratamento discriminatório à orientação sexual demonstra claro desrespeito aos princípios da dignidade humana e da isonomia, lesando o disposto pela Constituição Federal.

Não se pode falar em homossexualidade sem pensar em afeto. Enquanto a lei não acompanha a evolução da sociedade, as mudanças de mentalidade, a evolução do conceito de moralidade, ninguém tem o direito de fechar os olhos e assumir uma postura preconceituosa ou discriminatória, para não enxergar essa nova realidade. (DIAS, 2010, p. 5).

Ainda sobre os direitos fundamentais, incumbe referir o exposto por Sarlet.

Assim, percebe-se, desde logo, que o princípio da dignidade da pessoa humana não apenas impõe um dever de abstenção (respeito), mas também condutas positivas tendentes a efetivar e proteger a dignidade dos indivíduos. Nesta linha de raciocínio, sustenta-se, com razão, que a concretização do programa normativo do princípio da dignidade da pessoa humana incumbe aos órgãos estatais, especialmente, contudo, ao legislador, encarregado de edificar uma ordem jurídica que atenda às exigências do princípio. (2001, p. 109). 
Cumpre destacar o mencionado por Luís Roberto Barroso (2011, p. 6), ao referir que, a interpretação constitucional, como a interpretação jurídica em geral, não é um exercício abstrato de busca de verdades universais e atemporais. Toda interpretação é produto de uma época, de um momento histórico, e envolve as normas jurídicas pertinentes, os fatos a serem valorados, as circunstâncias do intérprete e o imaginário social.

As uniões afetivas entre pessoas do mesmo sexo são uma consequência direta e inevitável da existência de uma orientação homossexual. Por isso mesmo, também são um fato da vida, que não é interditado pelo Direito e diz respeito ao espaço privado da existência de cada um. (BARROSO, 2011, p. 8).

Barroso aduz sobre o fato de ser a homossexualidade um direito fundamental da pessoa tendo em vista o que dispõem os princípios constitucionais compatíveis com o direito homoafetivo.

\begin{abstract}
Os princípios são a expressão jurídica dos valores e dos fins de uma sociedade. Neles estão contidos os direitos fundamentais, não apenas com direitos subjetivos, mas, igualmente, como uma ordem objetiva de valores que deve inspirar compreensão e a aplicação do Direito. Em meio a esses princípios e direitos fundamentais encontram-se alguns que são decisivos para o enquadramento ético e jurídico da questão aqui enfrentada. Em primeiro lugar, o mandamento magno da igualdade, a virtude soberana, manifestado em inúmeras disposições constitucionais. Ao lado dele, o princípio da liberdade, que se colhe nos princípios da livre-iniciativa (cuja dimensão, relembre-se, não é apenas a de liberdade econômica) e da legalidade, bem como em referências expressas em todo o texto constitucional. (2011, p. 14).
\end{abstract}

Ainda, considera o autor como essencial ao respeito à homoafetividade, os princípios da dignidade da pessoa humana como fonte para os direitos fundamentais e para a efetivação dos direitos da personalidade, e, o princípio da segurança jurídica, que garante obviedade e solidez ao direito.

Todas as pessoas, a despeito de sua origem e de suas características pessoais, têm o direito de desfrutar da proteção jurídica que estes princípios lhes outorgam. Vale dizer: de serem livres e iguais, de desenvolverem a plenitude de sua personalidade e de estabelecerem relações pessoais com um regime jurídico definido e justo. E o Estado, por sua vez, tem o dever jurídico de promover esses valores, não apenas como uma satisfação dos interesses legítimos dos beneficiários diretos, como também para assegurar a toda a sociedade, reflexamente, um patamar de elevação política, ética e social. (BARROSO, 2011, p. 14-15).

Ainda no que diz com a proteção da dignidade, percebe-se a existência de consenso no sentido de que a consideração e o respeito pela pessoa como tal (inclusive antes mesmo do nascimento e independentemente de suas condições físicas ou mentais) constituem simultaneamente tarefa e limites intransponíveis para a ordem jurídica. (SARLET, 2001, p. 136). 
Sarlet (2001, p. 141), refere sobre a não violação do princípio da dignidade, o que se pode afirmar com alguma margem de certeza, renunciando a uma opção fechada em prol de uma ou outra concepção referida neste contexto, é que a busca de uma proteção eficaz da dignidade da pessoa (de todas as pessoas) de longe ainda não encontrou uma resposta suficientemente satisfatória para todos e se constitui em permanente desafio para aqueles que, com alguma seriedade e reflexão, se ocuparem do tema.

No que se refere à igualdade do ser humano como absoluta, Miguel Reale denota:

Daí parecer-me imprescindível acrescentar que "o ser do homem é o seu dever ser", tanto espiritual quanto corpóreo, cumprindo dar realce ao pronome seu, uma vez que não se cuida de determinar o significado do ser humano de maneira abstrata, mas na sua concreção, como principal senhor de seu destino e titular dos direitos que lhe são inerentes enquanto pessoa. (2005, p. 103).

Ainda que o avanço jurisprudencial seja categórico no sentido de conferir proteção aos homossexuais, muitas opiniões equivocadas permanecem arraigadas na cultura geral, impedindo a realização do anseio de igualdade de todos.

\section{DISCRIMINAÇÃO LÍCITA: FORMAS DE ALCANÇAR A IGUALDADE POR MEIO DE MOVIMENTOS SOCIAIS E DECISÕES JUDICIAIS}

Todo movimento social, manifestação ou protesto realizado, é um estímulo para que entrem em debate as ideias preconcebidas e as ideias geradas desta preconcepção, e, promover o debate e a correspondência de conhecimentos significa promover a cidadania e a igualdade entre os indivíduos, todos expressando a sua forma de pensar e de agir.

Conforme aduz Antônio Carlos Wolkmer,

$\mathrm{Na}$ pluralidade das experiências cotidianas, o ponto essencial dos movimentos sociais e das demais organizações comunitárias não-estatais não está na problemática de serem ou não institucionalizadas, mas na capacidade de romperem com a padronização opressora e de construírem uma nova identidade coletiva, de base participativa, apta à responder às necessidades humanas fundamentais. (1994, p. 129-130)

O autor fala também sobre o pluralismo em sua concepção filosófica. Parte-se do princípio de que existem muitas fontes ou fatores causais para explicar não só os fenômenos naturais e cosmológicos, mas igualmente, as condições de historicidade que cercam a própria vida humana (WOLKMER, 1994).

A compreensão filosófica do pluralismo reconhece que a vida humana é constituída por seres, objetos, valores, verdades, interesses e aspirações marcadas pela essência da 
diversidade, fragmentação, circunstancialidade, temporalidade, fluidez e conflituosidade (WOLKMER, 1994).

Ademais, ressalta que, o pluralismo, enquanto multiplicidade dos possíveis, provém não só da extensão dos conteúdos ideológicos, dos horizontes sociais e econômicos, mas, sobretudo, das situações de vida e da diversidade de culturas (WOLKMER, 1994).

Em se tratando das minorias e da atenção para as diferenças, aduz Jurgen Habermas:

O problema das minorias "inatas" explica-se pelo fato de que os cidadãos, mesmo quando observados como personalidades jurídicas, não são indivíduos abstratos, amputados de suas relações de origem. Na medida em que o direito intervém em questões ético-políticas, ele toca a integridade das formas de vida dentro das quais está enfronhada a configuração pessoal de cada vida. Com isso entram em jogo - ao lado de considerações morais, de reflexões pragmáticas e de interesses negociáveis valorizações fortes, que dependem de tradições intersubjetivamente compartidas, mas culturalmente específicas. (2007, p. 170-171)

Uma nação de cidadãos é composta de pessoas que, devido a seus processos sociais, encarnam simultaneamente as formas de vida dentro das quais se desenvolveu sua identidade - e isso ocorre mesmo quando, como adultos, eles se libertaram das tradições da sua origem. Naquilo que é relevante para seu caráter, as pessoas são como entroncamentos numa rede adscritícia de culturas e tradições. (HABERMAS, 2007, p. 171)

Os movimentos sociais, imprescindíveis na promoção da democracia, da participação social e da cidadania, reivindicam direitos em todas as suas perspectivas. Pode-se dizer que, essas manifestações projetam uma previsão do futuro nas mais variadas formas: seja por reinvindicações em prol do meio ambiente, questões trabalhistas, igualdade de gênero e valorização da identidade sexual de cada um, dentre outros direitos também importantes.

Nesse viés, Anthony Giddens refere que,

O poder, em seu sentido mais amplo, é um meio de conseguir que as coisas sejam feitas. Numa situação de globalização acelerada, procurar maximizar a oportunidade e minimizar os riscos de alta-consequência requer o uso coordenado do poder. Isto vale para a política emancipatória bem como para a política da vida. A solidariedade para com as aflições dos oprimidos é integral a todas as formas de política emancipatória, mas alcançar as metas envolvidas depende com frequência da intervenção da influência dos privilegiados. (1991, p. 161-162)

Ademais, cabe ressaltar que, é essencial reconhecer que, da perspectiva do realismo utópico, eles não são necessariamente a única base de mudanças que podem conduzir a um mundo mais seguro e mais humano. A perspectiva do realismo utópico reconhece a inevitabilidade do poder e não seu uso como inerentemente nocivo. (GIDDENS, 1991, p. 143)

Para Habermas, 
Estados democráticos de direito, apresentam-se, todavia, diversos caminhos para se chegar a uma inclusão "com sensibilidade para as diferenças": a divisão federativa dos poderes, uma delegação ou descentralização funcional e específica das competências do Estado, mas acima de tudo, a concessão de autonomia cultural, os direitos grupais específicos, as políticas de equiparação e outros arranjos que levem a uma efetiva proteção das minorias. Através disso, dentro de determinados territórios e em determinados campos políticos, mudam as totalidades fundamentais dos cidadãos que participam do processo democrático, sem tocar nos seus princípios. (2007, p. 172)

No que concerne à importância das ações afirmativas, Shirley de Miranda leciona que:

\begin{abstract}
As ações afirmativas podem ser entendidas como medidas públicas e privadas, coercitivas ou voluntárias, implementadas na promoção/integração de indivíduos e grupos sociais tradicionalmente discriminados em função de sua origem, raça, sexo, opção sexual, idade, religião, patogenia física/psicológica. As ações afirmativas são, portanto, atos de discriminação lícitos e necessários à ação comunicativa da sociedade. Logo, não devem ser vistas como "esmolas" ou "clientelismo", mas como um elemento essencial à conformação do Estado Democrático de Direito. São, pois, uma exigência comum a países desenvolvidos como os Estados Unidos e a países subdesenvolvidos como o Brasil. (2010, p. 28).
\end{abstract}

As ações afirmativas são denominadas discriminações lícitas em razão de elevar as minorias ao nível de igualdade dos demais através de algumas medidas permitidas por lei, a exemplo da política de cotas para o ingresso de negros e deficientes nas universidades. São benefícios outorgados a alguns grupos discriminados para que usufruam dos mesmos direitos dos demais, intentam estabelecer a isonomia entre todos, independentemente das diferenças.

No ano de 1995, houve uma ação afirmativa que, para a época, foi revolucionária. Souza Cruz (2003, p. 219) ilustra que, a mais significativa ação afirmativa em benefício dos homossexuais se constitui pelo Projeto de Lei n. 1.151, de 1995, de autoria da então deputada federal por São Paulo, Marta Suplicy. Entre outras conquistas, o projeto dispõe sobre regras da união civil entre duas pessoas do mesmo sexo, inclusive garantindo amplamente aos contratantes os direitos civis de sucessão regulados pela Lei n. 8971/94.

$\mathrm{Na}$ época não havia a perspectiva de que as uniões homoafetivas seriam consideradas famílias passíveis de tutela do Estado, mas já havia o embate no Congresso Nacional quanto à criação de legislação específica destinada ao reconhecimento dos direitos homossexuais.

Em 2015, foi retomada a discussão acerca do Projeto de Lei n. 122 chamado PL da Homofobia, arquivado no Senado. De sorte, outro Projeto de autoria da deputada federal pelo Rio Grande do Sul, Maria do Rosário, o PL 7582/2014 visa definir e punir os crimes de ódio e intolerância, ainda está sob apreciação. É mais uma ação que intui afirmar a garantia de se 
exercer o direito de liberdade sexual sem represálias. Na verdade, vai além dos direitos dos homossexuais, abrangendo a proteção das garantias de outras minorias, propondo combater discriminações por gênero, origem, classe social, raça ${ }^{8}$.

Neste viés, buscando promover a inclusão da comunidade LGBT, foi proposto o Estatuto da Diversidade Sexual como maneira efetiva de determinação dos direitos fundamentais e do princípio da não discriminação. O projeto objetiva, além de proteger os direitos dos LGBT's, combater a discriminação e criminalizar a homofobia, propondo políticas públicas que beneficiem aos homossexuais ${ }^{9}$.

Além das referidas políticas pautadas na inclusão dos homossexuais e demais minorias, cumpre destacar o trabalho dos julgadores no sentido de salvaguardar os direitos homoafetivos no que diz respeito a sua liberdade de expressão e a possibilidade de constituir família legítima de proteção, tudo com fundamento no reconhecimento às uniões homoafetivas já concedido pelo Supremo Tribunal Federal no ano de 2011.

Importante demonstrar alguns exemplos destas decisões.

A exemplo da concessão de pensão por morte a companheiro em relação homoafetiva, cabe ressaltar a apelação interposta pelo Instituto de Previdência do Estado do Rio Grande do Sul, da decisão que condenou a autarquia a pagar pensão por morte a companheiro sobrevivente em relação homoafetiva, alegando não restar comprovada a união estável, não preenchendo os requisitos para concessão do benefício.

$\mathrm{O}$ relator negou provimento ao recurso alegando que, consta pacificado o entendimento jurisprudencial no sentido de acolher os direitos resultantes do reconhecimento

\footnotetext{
${ }^{8}$ Art. $1^{\circ}$ Esta Lei define os crimes de ódio e intolerância e cria mecanismos para coibi-los.

Art. $2^{\circ}$ Toda pessoa, independentemente de classe e origem social, condição de migrante, refugiado ou deslocado interno, orientação sexual, identidade e expressão de gênero, idade, religião, situação de rua e deficiência goza dos direitos fundamentais inerentes à pessoa humana, sendo-lhe asseguradas as oportunidades para viver sem violência, preservar sua saúde física e mental e seu aperfeiçoamento moral, intelectual e social.

[...]

Art. $3^{\circ}$ Constitui crime de ódio a ofensa a vida, a integridade corporal, ou a saúde de outrem motivada por preconceito ou discriminação em razão de classe e origem social, condição de migrante, refugiado ou deslocado interno, orientação sexual, identidade e expressão de gênero, idade, religião, situação de rua e deficiência.

Pena - A prática de crime de ódio constitui agravante para o crime principal, aumentando-se a pena deste de um sexto até a metade.

${ }^{9}$ Art. $1^{\circ}$ - O presente Estatuto da Diversidade Sexual visa a promover a inclusão de todos, combater a discriminação e a intolerância por orientação sexual ou identidade de gênero e criminalizar a homofobia, de modo a garantir a efetivação da igualdade de oportunidades, a defesa dos direitos individuais, coletivos e difusos. Art. $2^{\circ}$ - É reconhecida igual dignidade jurídica a heterossexuais, homossexuais, lésbicas, bissexuais, transexuais, travestis, transgêneros, intersexuais, individualmente, em comunhão e nas relações sociais, respeitadas as diferentes formas de conduzirem suas vidas, de acordo com sua orientação sexual ou identidade de gênero.

Art. $3^{\circ}$ - É dever do Estado e da sociedade garantir a todos o pleno exercício da cidadania, a igualdade de oportunidades e o direito à participação na comunidade, especialmente nas atividades políticas, econômicas, empresariais, educacionais, culturais e esportivas.
} 
das famílias homoafetivas como idênticas às heteroafetivas, passíveis da mesma proteção pelo Estado.

Ainda, salientou que, além de estar comprovada a dependência econômica do cônjuge, se verifica a legitimidade constitucional da pensão por morte em união homoafetiva em decisão do Supremo Tribunal Federal, o que encerra quisquer dúvidas sobre o seu reconhecimento.

Assim, reconheceu a existência da união estável e dos requisitos caracterizadores da união e manteve a decisão de pagamento do benefício pelo Instituto de Previdência ${ }^{10}$.

Em outro caso também do Tribunal de Justiça gaúcho, foi observado o direito de adoção por um casal homoafetivo. Trata-se de apelação interposta pelo casal à decisão que julgou improcedente o pedido de adoção conjunta.

Para fundamentar o pedido, foram juntados todos os documentos necessários à habilitação e realizado o estudo social para avaliar as condições de receber uma criança. Porém, foi determinado às requerentes que indicassem apenas um nome pelo qual seria realizado o cadastro, visto que adoção somente seria permitida se fosse unilateral, não pelas duas mães.

O relator identificou que foram preenchidos todos os requisitos comprovando a união estável e a possibilidade de adotar. Ainda, explanou que o Direito precisa se adequar aos novos casos que estão surgindo e à realidade social atual. A jurisprudência vem conferindo às novas uniões o tratamento equivalente concedido às uniões heteroafetivas em uma variedade de julgados.

Em não havendo uma lei específica, os Tribunais se adequaram a realidade das novas formações familiares e vêm concedendo um amplo rol de direitos às famílias homoafetivas.

Nesse sentido, se há o reconhecimento das uniões entre pessoas do mesmo sexo, imprescindível que haja o mesmo reconhecimento para os direitos inerentes aos casais

10 APELAÇÃO CÍVEL. DIREITO PREVIDENCIÁRIO. IPERGS. PENSÃO POR MORTE. UNIÃO HOMOAFETIVA. HABILITAÇÃO DE COMPANHEIRO DE EX-SEGURADO. UNIÃO ESTÁVEL COMPROVADA. REQUISITOS PREENCHIDOS. HONORÁRIOS ADVOCATÍCIOS. MANUTENÇÃO DO QUANTUM FIXADO. I. Satisfatoriamente comprovada a convivência entre o autor e o ex-segurado, como se casados fossem, deve o mesmo ser habilitado como pensionista junto ao Instituto de Previdência. Ademais, a dependência econômica é condição indispensável para o percebimento da pensão previdenciária pelo companheiro de ex-segurado do IPERGS. Tendo em vista a comprovação da dependência econômica pelo autor, este tem o direito ao recebimento do benefício de pensão por morte. II. Honorários advocatícios bem dimensionados, levando em conta o parágrafo $4^{\circ}$ do art. 20 do CPC. Apelos desprovidos. (Apelação Cível N $^{\circ}$ 70061713079, Vigésima Primeira Câmara Cível, Tribunal de Justiça do RS, Relator: Marco Aurélio Heinz, Julgado em 17/12/2014) 
homoafetivos, como a adoção homoparental. Ainda, salienta-se a inexistência de vedação legal para a hipótese de adoção por duas pessoas do mesmo sexo, se comprovada a estabilidade da relação.

Além disso, restou esclarecido que não pode haver distinção à conduta homossexual em respeito ao próprio princípio da isonomia, e, em se tratando de caso de adoção, o bem-estar da criança deve ser levado em conta, não o sentimento desgastante de discriminação, de modo que aceitar a adoção homoparental possibilita que mais crianças sejam abrigadas por uma família. Por fim, o recurso foi provido. ${ }^{11}$

O que se denota das decisões e das propostas de inclusão definitiva das diversidades, é que ambas visam a satisfação dos direitos da coletividade, priorizam a igualdade de todos através de políticas benéficas às minorias discriminadas e intentam atingir de forma ampla os princípios dispostos na Constituição Federal.

\section{CONSIDERAÇÕES FINAIS}

É possível evidenciar, de acordo com as ideias desenvolvidas, que, as uniões homoafetivas são uma realidade social e é dever do Estado contribuir para que sejam consideradas no plano dos direitos, respeitadas e tratadas com a igualdade de garantias das uniões heteroafetivas.

A orientação sexual não é definida por padrões impostos pela sociedade essencialmente heteroafetiva, mas pela personalidade de cada pessoa, todos devem ter garantida sua liberdade ao exercício da sexualidade.

Pode ser constatado que, ainda que a proteção do Poder Judiciário aos homossexuais seja constante, as atitudes discriminatórias ganham muita força; ao se analisar o

\footnotetext{
11 APELAÇÃO CÍVEL. PEDIDO DE HABILITAÇÃO À ADOÇÃO CONJUNTA POR PESSOAS DO MESMO SEXO. ADOÇÃO HOMOPARENTAL. POSSIBILIDADE DE PEDIDO DE HABILITAÇÃO. Embora a controvérsia na jurisprudência, havendo possibilidade de reconhecimento da união formada por duas pessoas do mesmo sexo como entidade familiar, consoante precedentes desta Corte, igualmente é de se admitir a adoção homoparental, inexistindo vedação legal expressa à hipótese. A adoção é um mecanismo de proteção aos direitos dos infantes, devendo prevalecer sobre o preconceito e a discriminação, sentimentos combatidos pela Constituição Federal, possibilitando, desse modo, que mais crianças encontrem uma família que lhes conceda afeto, abrigo e segurança. Estudo social que revela a existência de relacionamento estável entre as habilitandas, bem como capacidade emocional e financeira, sendo favorável ao deferimento da habilitação para adoção conjunta, nos termos do $\S 2^{\circ}$ do art. 42 do ECA, com a redação dada pela Lei 12.010/2009. DERAM PROVIMENTO À APELAÇÃO. (SEGREDO DE JUSTIÇA) (Apelação Cível No 70031574833, Sétima Câmara Cível, Tribunal de Justiça do RS, Relator: André Luiz Planella Villarinho, Julgado em 14/10/2009)
} 
número lamentavelmente expressivo de crimes de ódio que ocorrem no Brasil com frequência, percebe-se que ainda há muito a ser feito, o tema da homoafetividade será sempre envolto de discussões sendo necessário que hajam o máximo de ações afirmativas visando beneficiar as minorias.

O Supremo Tribunal Federal reconhece as uniões homoafetivas como passíveis de proteção do Estado e, em suas decisões salientou o exposto pela Constituição Federal ao expressar de forma veemente os princípios basilares para se alcançar a equidade, com ênfase para o princípio da dignidade da pessoa humana.

Importa, tornar efetivos os princípios trazidos pela Constituição e transpor os obstáculos criados pela discriminação infundada, para que a igualdade tão aclamada saia dos discursos e funcione para a totalidade das pessoas.

\section{REFERÊNCIAS}

BARROSO, Luís Roberto. Diferentes, mas iguais: o reconhecimento jurídico das relações homoafetivas no $\quad$ Brasil. $2011 . \quad$ Disponível bibliotecadigital.mpf.mp.br/bdmpf/handle/11549/7810?show=full Acesso em 22/09/2016.

BERNARDET, Jean-Claude. 12 Faces do preconceito. Organizador Jaime Pinsky. São Paulo: Editora Contexto, 2010.

Bioética: introdução. Disponível em <http://www.ghente.org/bioetica/ > Acesso em 20/09/2016.

BRASIL. Constituição da República Federativa do Brasil. Disponível em: www.planalto.gov.br/ccivil_03/Constituicao/Constituicao.htm Acesso em 20/09/2016.

Supremo Tribunal Federal. ADI 4.277. Disponível em http://redir.stf.jus.br/paginadorpub/paginador.jsp?docTP=AC\&docID=628633 Acesso em 20/09/2016.

Supremo Tribunal Federal. RE 846102 - RECURSO EXTRAORDINÁRIO. Disponível em http://s.conjur.com.br/dl/stf-reconhece-adocao-restricao-idade.pdf Acesso em 20/09/2016.

CONSELHO NACIONAL DE JUSTIÇA. Disponível em http://www.cnj.jus.br///images/atos_normativos/resolucao/resolucao_175 Acesso em 20/09/2016.

DIAS, Maria Berenice. Direito fundamental à homoafetividade. 2010. Disponível em www.mbdias.com.br Acesso em 22/09/2016. 
Homoafetividade e Direito homoafetivo. 2010. Disponível em www.mbdias.com.br Acesso em 22/09/2016

Estatuto da Diversidade Sexual. Disponível em <www.direitohomoafetivo.com.br/> Acesso em 22/09/2016.

FOUCAULT, Michel. História da sexualidade. A vontade de saber. Tradução de Maria Thereza da C. Albuquerque e J.A. Guilhon Albuquerque. Rio de Janeiro: Edições Graal, 1997.

História da sexualidade. O uso dos prazeres. Tradução de Maria Thereza da C. Albuquerque. Rio de Janeiro: Edições Graal, 1994.

GEERTZ, Clifford. A interpretação das culturas. Rio de Janeiro: LTC, 1989.

GIDDENS, Anthony. As consequências da modernidade. Tradução de Raul Fiker. São Paulo: Editora Unesp, 1991.

HABERMAS, Jurgen. A inclusão do outro. Estudos de teoria política. Tradução de George Sperber, Paulo A. Soethe e Milton C. Mota. São Paulo: Edições Loyola, 2007.

MIRANDA, Shirley Aparecida de. Diversidade e ações afirmativas: combatendo as desigualdades sociais. Belo Horizonte: Autêntica Editora, 2010.

O significado LGBT. Disponível em http://www.lgbt.pt/significado-lgbt/ Acesso em 22/09/2016.

PIOVESAN, Flávia. RIOS, Roger Raupp. A discriminação por gênero e por orientação sexual. Disponível em <daleth.cjf.jus.br/revista/seriecadernos/vol24/artigo05.pdf>Acesso em 22/09/2016.

Projeto de Lei n. 7.582/2014. Disponível em www.camara.gov.br/sileg/integras/1254961.pdf Acesso em 22/09/2016.

REALE, Miguel. O Estado democrático de Direito e o conflito das ideologias. $3^{\mathrm{a}}$ ed. São Paulo: Saraiva, 2005.

RIO GRANDE DO SUL. Apelação Cível No 70061713079, Vigésima Primeira Câmara Cível, Tribunal de Justiça do RS, Relator: Marco Aurélio Heinz, Julgado em 17/12/2014 Disponível em http://www.tjrs.jus.br/busca/search?q=70061713079 Acesso em 22/09/2016.

Apelação Cível No 70031574833, Sétima Câmara Cível, Tribunal de Justiça do RS,

Relator: André Luiz Planella Villarinho, Julgado em 14/10/2009. Disponível em http://www.tjrs.jus.br/busca/search?q=70031574833 Acesso em 22/09/2016.

SARLET, Ingo Wolfgang. A eficácia dos direitos fundamentais. Quarta edição. Porto Alegre: Livraria do Advogado Editora, 2004.

Dignidade da pessoa humana e direitos fundamentais na Constituição Federal de 1988. Porto Alegre: Livraria do Advogado Editora, 2001. 
SOUZA CRUZ, Álvaro Ricardo de. O direito à diferença. As ações afirmativas como mecanismo de inclusão social de mulheres, negros, homossexuais e pessoas portadoras de deficiência. Belo Horizonte: Del Rey, 2003.

WOLKMER, Antônio Carlos. Pluralismo jurídico. Fundamentos de uma nova cultura no Direito. São Paulo: Editora Alfa Ômega, 1994 